\title{
Peste en Milán: Borromeos y untadores
}

\author{
WALTER LEDERMANN D.
}

\section{Plague in Milan: borromeans and smearers}

Dos brotes importantes de plaga sufrió Milán en los siglos XVI y XVII, y dos fueron los religiosos de la familia Borromeo que combatieron con denuedo este mal: San Carlos, primero, y luego su célebre primo, el Cardenal-Arzobispo Federico; aquél con fe, esperanza y caridad; éste con un leve toquecillo infectológico.

Los Borromeo constituían por entonces una ilustre familia de la Toscana, cuyo nombre se recuerda por San Carlos y por las Borromeas, cuatro bellísimas islas en la bahía oeste del Lago Maggiore, su más preciada posesión. Isola Bella, la más famosa, cuyo sólo nombre trae a la imaginación cielos luminosos y atardeceres deslumbrantes, era una roca desolada hasta 1650, cuando los condes Carlos (no confundir con el santo) y Giulio llevaron tierra fértil desde el continente, para que más tarde la condesa Vitaliana la plantara con árboles tropicales, cubriendo de variadas flores diez terrazas que miran hacia el mar; un palacio repleto de pintura lombarda, tapicería flamenca y colecciones de armas y muebles completan su encanto turístico ${ }^{1}$.

Carlos Borromeo (1538- 1584) fue designado Arzobispo de Milán a los 26 años, diócesis que ya administraba por lo demás desde los 22, habiendo participado activamente, como Secretario de Estado de Pio IV, en la reanudación del Concilio de Trento. En el 1577 la peste negra apareció en el milanesado: según los cronistas de la época, la Yersinia pestis (entonces desconocida, pero intuida por observadores sagaces) solía visitar la península de Italia un par de veces cada siglo; esta sería, entonces, la segunda visita del XVI. De la primera no hay constancia; la segunda fue célebre por la figura del santo, tanto que se la conoce como "la peste de San Carlos". Tan grande es el poder de la caridad -dice un novelista- que puede hacer sobresalir el recuerdo de un hombre por haber inspirado sentimientos y acciones más memorables que los mismos males; puede grabar su nombre en los ánimos como una señal de todos aquellos acontecimientos, por haberlos estimulado y dirigido como guía, auxilio, ejemplo y víctima voluntaria, y hacer de una calamidad general una empresa gloriosa para este mismo hombre, designándola como si fuera una conquista o un descubrimiento suyo ${ }^{3}$.

Innumerables son las anécdotas y las historias atribuidas al Arzobispo en su lucha contra la plaga, que al fin se cobró su vida el 3 de noviembre de 1584 , siendo canonizado el 4 de noviembre de 1610, ma- yormente por los milagros obtenidos durante la epidemia. Sepan los Carlos actuales que cuando se les abraza el 4 de noviembre, porque "están de santo", es en memoria de aquel Borromeo que luchó contra la peste armado sólo de su bondad.

Federico Borromeo (1564-1631) era milanés, discípulo de San Filippo Neri y primo de San Carlos, quien lo recomendó para Cardenal, dignidad que ejerció entre 1587 y 1595. Se le recuerda fundamentalmente por dos razones: por la creación de la $\mathrm{Bi}$ blioteca Ambrosiana, una de las más ricas colecciones de libros y manuscritos que registra la historia del conocimiento, acción que le valió sin duda buena parte de los quince votos que obtuvo en el cónclave de 1623, donde fue derrotado por el Cardenal Barberini (Urbano VIII); y por la heroica lucha contra la peste que libró hacia el final de su existencia ${ }^{4}$.

La epidemia que le tocó enfrentar se inició en 1628 , cuando ya contaba con 64 años. Fue favorecida por la estupidez humana, expresada a través de la torpeza y corrupción de las autoridades y de la ceguera médica. En primer lugar, había guerra; en segundo, y como consecuencia, hambruna y migración a las ciudades. La guerra tenía -¿nos molestaremos en decirlo?- causas eran tan fútiles como siempre y respondían a la ambición algunos figurones. Habiendo fallecido el duque Vicente Gonzaga II, varios candidatos surgieron para ocupar Mantua y Monteferrato, los dos estados que poseía en Italia. España, Francia (con el cardenal Richelieu), la República de Venecia y el Papa Urbano VIII, apoyaban unos a Felipe Gonzaga, duque de Nevers, otros a Carlos Manuel I, duque de Saboya, y los menos a Margarita Gonzaga, duquesa de Lorena; a quienes leyeron en su juventud las aventuras del famoso espadachín Lagardère, estos Gonzaga y Nevers deben sonarles familiares ${ }^{5}$. Los detalles de sus nombres y vanidades no pueden entrabar esta historia y bástenos decir que en algún momento el Tribunal de Sanidad de Milán debió enfrentar la posibilidad que tropas alemanas, ya en Italia, entraran al milanesado, siendo hecho conocido que portaban la peste, pues a su paso por las distintas ciudades dejaban una curiosa enfermedad que diezmaba las poblaciones, y "decían los ancianos ser la peste, por haberla vivido anteriormente".

El protomédico Luigi Settala, profesor de medicina de la Universidad de Pavía y de filosofía moral en la de Milán, que de joven había luchado contra la epidemia anterior, advirtió oportunamente al Tribu- 
nal para que tomase medidas, pero éste prefirió enviar un par de médicos a investigar en el terreno. Aunque éstos trabajaron con la mayor acuciosidad, luego dijeron algunos colegas que les tenían inquina, que se habían "dejado engañar por un barbero viejo", descalificando así a un anciano cirujano de un poblado vecino; es el caso que regresaron diciendo que las muertes se debían, en algunos lugares, a las emanaciones pútridas de los pantanos, y en otras, a los excesos de los alemanes. Pero, como las noticias eran cada vez más alarmantes y los germanos estaban más cerca, se envió a otro médico célebre, Tadino, quien confirmó los más negros temores y en cuyo testimonio nos apoyaremos frecuentemente en este artículo ${ }^{6}$. Alertado Ambrosio Espínola, quien gobernaba interinamente en nombre de España, respondió que eran más urgentes los negocios de la guerra: Sed belli, gaviore esse cures. Y en lugar de cerrar la ciudad, la abrió para celebrar el natalicio del príncipe Carlos, primogénito de Felipe IV, lo que dio ocasión para que acudiesen desde los pueblos vecinos "muchedumbres ávidas de pan y diversiones"7.

El año 1628 había sido de gran hambruna, tanto por las malas cosechas como por la devastación causada en los campos por las tropas de uno y otro pretendientes. Don Gonzalo, el gobernador anterior, para mejorar las cosas, fijó al pan un precio que era un tercio del costo. Ignoraba don Gonzalo los principios básicos del libre mercado: el bajo precio fomentó la demanda a extremos imposibles de satisfacer, los panaderos no dieron abasto, las amasaderías fueron asaltadas y destruidas, mayores fueron el hambre y la penuria. Las autoridades reunieron, para socorrerlos mejor, a los más hambrientos y depauperados en el antiguo lazareto, donde se hacinaron por miles. El caldo estaba listo: faltaba el inóculo. El 22 de octubre éste llegó con la entrada en Milán de Pedro Antonio Lovato, soldado italiano al servicio de España, que estaba de guarnición en Lecco y quiso asistir a las fiestas. Aunque el Cardenal Federico Borromeo ya se había adelantado, enviando una circular a los párrocos para quemar las ropas de los enfermos, el Tribunal no había estado tan ágil en el sentido de prohibir la compra ventajosa de vestimenta a los alemanes, de manera que el soldado entró con un gran lío de ropa comprada o robada a los invasores y lo dejó en casa de su tío Giancarlo, quien fue a parar al hospital con un bubón axilar. El Tribunal ordenó quemar su cama y vestidos, pero era demasiado tarde: murieron los dos practicantes y el sacerdote que asistieron al enfermo y la peste se extendió ${ }^{8}$.

Se produjo en la ciudad un curioso fenómeno de negación de la evidencia, al que cooperaron incluso algunos médicos, quienes, no queriendo reconocer que se habían equivocado, para evitar la vergüenza acarreada por su ignorancia, hablaban de fiebres pestilentes. El profesor Settala, campeón de la teoría de la peste contagiosa, fue apedreado por una turba que lo acusaba de atemorizar con una plaga inexistente a fin de aumentar su consulta y así enriquecerse con el terror de la población; más, cuando el mismo protomédico, su mujer, dos hijos y siete criados cayeron enfermos, comenzó la plebe a dudar... pero el convencimiento total nunca llegó, gracias a los imaginarios untadores.

Cuando los porfiados no encuentran apoyo en los hechos reales, recurren a los imaginarios. Entre las ideas populares de la época estaban las de los maleficios, estimándose posible que la peste se introdujese por hechizos o por envenenamientos, tanto que ya el año anterior el rey Felipe IV había enviado un oficio al Gobernador interino de Milán, advirtiéndole que habían entrado a Italia unos franceses, escapados de Madrid, que esparcían ungüentos venenosos y pestíferos. La situación era explosiva y faltaba sólo una chispa. El 17 de mayo, casi siete meses después del inóculo de la Yersinia pestis por el soldadito con su hatillo de ropa alemana, ocurrió un hecho banal e inocente, que desencadenó una tragedia.

Algún amante de la limpieza pasó un paño por la barandilla de madera que, en la catedral, separaba los bancos de las mujeres y de los hombres. Quienes lo vieron, corrieron al Tribunal, denunciando que no sólo la barandilla había sido untada, sino también las bancas; el Tribunal, en un exceso de celo, sacó a la calle barandas y gran número de bancas, que más tarde serían quemadas sin mucha reflexión, dando crédito al populacho. Al día siguiente numerosas casas exhibían en sus puertas y ventanas manchones amarillo-blanquecinos, hechos al parecer con una esponja. ¿Una broma estúpida de los joviales muchachos de la época ? El espanto cundió en la ciudad y todo individuo que por su vestimenta o su lengua pareciese extranjero, era detenido y llevado a la cárcel, sospechoso de ser untador, pero a ninguno pudo probarse tan nefando delito. Experiencias realizadas en perros, bajo la dirección de Settala, con la sustancia supuestamente untada - una especie de jaboncillo pegajoso - arrojaron resultados negativos. Pero el mal estaba hecho y comenzó una siniestra cacería de untadores, que duró mientras la epidemia persistió9.

Paul D' Ethieu, un joven escritor francés, viajando por Italia con el pintor Jean Suffert y un amigo de éste, se encontraba en Milán cuando ocurrió el supuesto untamiento de los bancos de la catedral. Sin hacer caso del amontonamiento de madera que llenaba la plazoleta, Paul discutía acaloradamente con Suffert, sentado al desgaire encima de una de las bancas proscritas, sobre la naturaleza del material empleado en un marco de la pared poniente:

- C'est marbre - decía el escritor.

-Mais, non! Touchez ici - tuvo la mala idea de rebatir el pintor, poniendo mano sobre la muralla, la misma que descansaba recién sobre el brazuelo de la banca.

— ¡Untadori ! - gritó una donna histérica.

De inmediato, el gentío que se había ido reuniendo alrededor de estos extranjeros, ya sospechosos por sus misteriosas carteras de cuero, su ausencia de temor por las bancas envenenadas y su minucioso examen de los muros, se abalanzó sobre los infortunados artistas, arrastrándolos a golpes hasta 
el palacio de justicia, donde por fortuna encontraron lo que raramente hallaban los inocentes en esos lugares y fueron liberados, no sin algunas magulladuras y hematomas. Otros, menos afortunados, pagaron su vida conductas atípicas ${ }^{10}$.

Aunque ya se había pasado del término "fiebres pestilentes" a una "enfermedad similar a la peste", ni pacientes ni médicos, ni mucho menos las autoridades, querían reconocer la presencia de la peste. El Tribunal, el porfiado y testarudo Tribunal, terminó por convencerse al fin y transmitió ese convencimiento a la población de la manera más atroz. Para la Pascua de Pentecostés solían las familias concurrir al cementerio de San Gregorio, fuera de la Puerta Oriental de Milán, donde reposaban los muertos de la epidemia anterior, ocasión en que todos solían vestir sus mejores galas y mostrar un regocijo impropio del lugar. El Tribunal esperó a que estuviera reunida la mayor muchedumbre, e hizo pasar entre ella un carro con los cadáveres desnudos de toda una familia fallecida el día anterior, "para que todos pudiesen ver las asquerosas y positivas señales de la peste". Esta terapia de shock valió por mil bandos y la presencia en Milán de la peste fue aceptada, pero a la idea del contagio se había sumado la idea del veneno y del maleficio: el unto.

Federico Borromeo, el Cardenal-Arzobispo, creía en la peste y en el "contagio", esto es, un agente miasmático, imposible de definir, aprehender o imaginar en esa época pre-bacteriológica. Pero, espíritu amplio y abierto, dudaba y no excluía, al principio, la posibilidad del veneno untado. Si fue el primero en tomar medidas epidemiológicas, disponiendo la quema de ropa y el aislamiento de los enfermos, se negó a los pedidos de la autoridad civil para combatir la peste prestando el cuerpo de San Carlos para una procesión salvadora. Expresó sabiamente que, si había untadores, una masiva procesión sería ocasión pintada para que cometieran sus untos; y que, si no los había, la concurrencia de mucha gente facilitaría el contagio, riesgo mucho más cierto ${ }^{11}$. Pero la presión de las autoridades, apoyadas sutilmente por las armas, fue tremenda, y Borromeo terminó por ceder, sin duda para evitar males mayores, y permitió exponer durante ocho días el cadáver de su santo primo en el altar mayor. El Tribunal de Sanidad aceptó la exhibición, pero hizo cerrar las puertas de la ciudad a los extranjeros y clavar las puertas y ventanas de las casas de los apestados, que eran unas quinientas.

La procesión se hizo. Fue inmensa, magnífica, lujosa, atravesó la ciudad y desde las ventanas enfermos y sanos saludaban al cadáver del santo. El resultado fue espantoso: al día siguiente creció el número de casos en forma abrupta y masiva, como nadie hubiera podido siquiera imaginar. $\mathrm{Y}$ aunque el Tribunal y Borromeo lo atribuyeron a la facilitación de un contagio masivo, "persona a persona", dijo la gente que se debía a untadores infiltrados, quienes habían dispersado polvos venenosos ${ }^{12}$.

La catástrofe fue total. Los muertos pasaban de quinientos diarios y el lazareto aumentó de dos mil a doce mil pacientes. Según Tadino, la mortalidad lle- gó en su peor momento a tres mil quinientos por día y el lazareto a quince mil enfermos. El temor a los untadores desarrolló algunas conductas prácticas: nadie usaba capa, para evitar que su ruedo rozara accidentalmente algún unto, ni tampoco llevaban hábito o sotana los religiosos, movilizándose laicos y sacerdotes con la ropa ceñida al cuerpo, por el centro de la calle, porque no les cayese algún polvo de los balcones; iban los caballeros sin séquito a las compras y los amigos se saludaban desde lejos, evitando la menor reunión social; todos portaban vinagre en un paño, con el cubrían de tanto en tanto sus narices, para evitar las emanaciones; nadie se cortaba barba ni cabello, pues los barberos tenían fama de untadores... (¿no les recuerda algunas aprensiones actuales a raíz del SIDA?). La creencia en el poder desinfectante del vinagre, así como de esencias olorosas y penetrantes, estaba muy extendida. Por la misma época el célebre médico francés Chicogneau diseñó, con ocasión de la epidemia de Marsella, un curioso traje de infectólogo, en que sobresalía una máscara en pico de loro, en cuyo interior el doctor ponía una buena cuota de vinagre $^{13}$.

Los carros mortuorios eran arrastrados por unos miserables rapaces y sin conciencia, llamados monatos, quienes entraban a saco en las casas marcadas por la peste y despojaban de su bienes a los enfermos y a los contactos: no morían, bien porque solían reclutarse entre quienes, habiendo sufrido la peste, la habían sobrevivido, bien porque, quizás, no perteneciendo cabalmente al género humano, eran inmunes o refractarios... En una ocasión, viendo que en un carro iba, entrelazada con cadáveres malolientes, una joven febril pero aún viva, el Cardenal se atravesó en su camino para detenerlo, sosteniendo luego una larga conversación con el jefe de los monatos, a quien no sólo logró convencer del contagio persona a persona, haciéndole desembarcar a su pasajera en el lazareto, sino también regenerar, "tornándolo al seno amoroso de la Iglesia". Como en el lazareto había secciones "sanas", que albergaban supuestos contactos, es posible que esta generosa acción de Borromeo haya causado un desastre, al meter al bacilo en el interior de un bello caballo de Troya, pero la intención es lo que vale.

Federico Borromeo entregó la administración del lazareto a los capuchinos, encabezados por el heroico padre Félix Casatti, lo cual fue un gran avance y salvó innumerables vidas. También colaboró el clero organizando cuadrillas de sepultureros, recogiendo cadáveres y cavando fosas con un amor que jamás hubieran imaginado los siniestros monatos. Y si los médicos del lazareto se extinguieron muy rápido (no había muchos por entonces) los religiosos, que asumieron las funciones terapéuticas y de enfermería, sufrieron pérdidas más horrorosas, muriendo "ocho de cada nueve" y "más de sesenta párrocos". Federico vio a su alrededor como desaparecían sus familiares y amigos, pero se resistió a retirarse a una quinta vecina al Lago Maggiore (Isola Bella no era habitable en esa época), permaneciendo en la ciudad, visitando los enfermos y recorriendo las calles, 
exhortando al clero a cumplir con sus funciones, metiéndose una y otra vez al lazareto y a las casas condenadas. Convencido del contagio como verdadero mecanismo de trasmisión, desechando definitivamente la fábula de los untadores, admirábase este Borromeo "de haber salido con bien". Su fortuna no salió, en todo caso ilesa, pues socorrió generosamente de su bolsillo a la ciudad entera, comprando todo el grano necesario y manteniendo siempre su puerta y su bolsa abiertas a todos las veinticuatro horas del día. Había seleccionado seis frailes de entre los más robustos, por estimarlos con mayores posibilidades de sobrevivir a la plaga, los enviaba día a día, divididos en tres parejas, cargados de víveres y de consuelos para repartir puerta a puerta entre los necesitados, no importando si estas puertas estaban clavadas. Estas parejas, por cierto, debieron renovarse más de una vez ${ }^{14}$.

Murió la mayor parte de la población y el resto quedó empobrecida. La ciudad, desierta y ruinosa, quemadas las puertas y ventanas de los hogares para combatir el unto, tomaría años en recuperarse. De los médicos, entrarían a la historia los nombres de Luigi Settala y Alessandro Tadino, infectólogos improvisados y esforzados, en tanto que untadores y monatos entrarían al folclor de la Toscana. De los religiosos, el padre Casatti enfermó mientras dirigía el lazareto, pero sobrevivió para ver morir a casi todos sus compañeros: por el resto de sus días lamentó "haber hecho tan poco". Y en cuanto a Federico Borromeo, si no fue santificado como Carlos, hasta la Yersinia pestis, que no distingue moros ni cristianos, se hizo a un lado y lo saludó con respeto cuando lo vio venir, con la capa al viento, despreciando al unto imaginario, para llevar consuelo a la puerta de algún contacto, condenado irremediablemente a morir en una casa clausurada.

\section{Bibliografía}

1.- Ryan E A. Borromean Islands. En Collier's Encyclopedia. Crowell Collier and MacMillan, Inc, USA 1967; 4: 400.

2.- Spillmann J. La peste de San Carlos. Editorial Difusión, Buenos Aires 1947; pp 1- 15.

3.- Manzoni A. Los novios (I promisi sposi ). Ramón Sopena S.A., Barcelona 1975; p 420.

4.- Ryan E A. Borromeo, Federigo. En Collier's Encyclopedia. Crowell Collier and MacMillan, Inc, USA 1967; 4: 401.

5.- Feval P. Le bossu. XVI édition. Librairie Hachette et Cie, Paris 1925.

6.- Monasco A. Alessandro Tadino. Ragguaglio dell' origine et giornali succesi della gran peste contagiosa, venefica et malefica, seguita nella città di Milano 1630. Allegri Ed., Milano 1948, pp 10, 24-25, 93-6.

7.- Monasco, A. Josephi Ripamonti. De peste quae fuit anno 1630. Allegri Ed., Milano 1951; pp. 59-78.

8.- Verri P, Storia di Milano. Presse Italica, Milano 1825; IV: 155. Citado en: Blanchard, R. Traité des Maladies Contagieuses. Librairie J.B. Baillière et fils, Paris 1890; II: $603-4$.

9.- Agostino Lampugnano. La pestilenza seguita in Milano l'anno 1630. Milano 1634. En : Favaro, A. Annales de la peste noir. J. Rueff, éditeur, Paris 1906; pp. 212-3.

10.- Taine H. Voyage en Italie. Compilation anecdotique ajouté au treizième édition.Librairie Hachette et Cie, Paris, 1907; III: 333-4.

11.- Verri P. Observazione sulla tortura : Scrittori italiani d'economia politica. Impronta, Milano 1837; XVII: 203-8. Citado en: Blanchard, R. Traité des Maladies Contagieuses. Librairie J.B. Baillière et fils, Paris 1890; II: 605 .

12.- Muratori T. Del governo della peste. Modena 1814; I: 117-8.

13.- Cover. Clin Infect Dis 2002

14.- Manzoni A. La colonna infame. XII ed., Roma 1948; pp. 107-9. 